\title{
Article
}

\section{NECTIN4: A Novel Therapeutic Target for Melanoma}

\author{
Yuka Tanaka ${ }^{1,+}+\mathbb{D}$, Maho Murata ${ }^{1,+} \mathbb{D}$, Che-Hung Shen ${ }^{2}$, Masutaka Furue ${ }^{1,3}$ and Takamichi Ito ${ }^{1, * \mathbb{D}}$ \\ 1 Department of Dermatology, Graduate School of Medical Sciences, Kyushu University, \\ Fukuoka 812-8582, Japan; yukat53@med.kyushu-u.ac.jp (Y.T.); \\ muratama@dermatol.med.kyushu-u.ac.jp (M.M.); furue@dermatol.med.kyushu-u.ac.jp (M.F.) \\ 2 National Institute of Cancer Research, National Health Research Institutes, Tainan 70456, Taiwan; \\ chshen@nhri.org.tw \\ 3 Research and Clinical Center for Yusho and Dioxin, Kyushu University Hospital, Fukuoka 812-8582, Japan \\ * Correspondence: takamiti@dermatol.med.kyushu-u.ac.jp; Tel.: +81-92-642-5585 \\ + These authors contributed equally to this work.
}

check for

updates

Citation: Tanaka, Y.; Murata, M.; Shen, C.-H.; Furue, M.; Ito, T. NECTIN4: A Novel Therapeutic Target for Melanoma. Int. J. Mol. Sci. 2021, 22, 976. https://doi.org/ 10.3390/ijms22020976

Academic Editor: Karel Smetana

Received: 5 January 2021

Accepted: 17 January 2021

Published: 19 January 2021

Publisher's Note: MDPI stays neutral with regard to jurisdictional claims in published maps and institutional affiliations.

Copyright: (C) 2021 by the authors. Licensee MDPI, Basel, Switzerland. This article is an open access article distributed under the terms and conditions of the Creative Commons Attribution (CC BY) license (https:// creativecommons.org/licenses/by/ $4.0 /)$.

\begin{abstract}
Malignant melanoma is the most common lethal skin cancer and causes death in a short time when metastasized. Although BRAF inhibitors (BRAFi) have greatly improved the prognosis of BRAF-mutated melanoma, drug resistance is a major concern even when they are combined with MEK inhibitors. Alternative treatments for BRAFi-resistant melanoma are highly anticipated. Nectin cell adhesion molecule 4 (NECTIN4) is highly expressed and associated with progression in tumors. We aimed to investigate the role of NECTIN4 in melanoma and its potency as a therapeutic target using 126 melanoma samples and BRAFi-resistant cells. Immunohistochemically, most of the clinical samples expressed NECTIN4, at least in part. NECTIN4 was highly expressed in BRAF-mutated melanoma and its high expression was associated with disease-free survival. In BRAFi-resistant melanoma cells, NECTIN4 and the PI3K/Akt pathway were upregulated, along with the acquisition of BRAFi resistance. Monomethyl auristatin E, a cytotoxic part of NECTIN4-targeted antibodydrug conjugate, was effective for BRAF-mutated or BRAFi-resistant melanoma cells. NECTIN4 inhibition increased the sensitivity of BRAFi-resistant cells to BRAFi and induced apoptosis. In conclusion, we revealed the expression and roles of NECTIN4 in melanoma. Targeted therapies against NECTIN4 can be a novel treatment strategy for melanoma, even after the acquisition of BRAFi resistance.
\end{abstract}

Keywords: NECTIN4; malignant melanoma; antibody-drug conjugate; BRAF; BRAFi resistance

\section{Introduction}

Malignant melanoma is one of the most common lethal skin cancers, arising from melanocytes. In recent decades, the incidence of melanoma has been increasing worldwide and the estimated annual increase in its incidence is approximately 3-7\% for Caucasians [1-3]. Most melanomas are cutaneous types and frequently occur in sunlight-exposed areas, since ultraviolet exposure is a known risk factor [1,2]. Although localized melanomas can be treated by surgical excision (5-year survival rate $>90 \%$ ), melanoma frequently becomes invasive and metastasizes. Dacarbazine-based chemotherapy or radiation therapy used to be applied for unresectable melanoma, but the efficacy was low (survival rate $<10 \%$ ) $[4,5]$. In recent years, immune checkpoint inhibitors (ICI), such as PD-1 inhibitors (nivolumab, pembrolizumab) and a CTLA4 inhibitor (ipilimumab), have been applied for the treatment of advanced melanoma, which dramatically improved the prognosis of patients [6,7]. However, there is still a subset of patients with primary/acquired drug resistance [8,9], indicating the urgent need for alternative treatments.

As is usually observed in cancers, gene mutations have been found in melanoma, such as in BRAF, KIT, NF, NRAS, and PTEN [10]. In particular, the mutational activation of BRAF is observed at a high frequency (about 50\%) and $\mathrm{BRAF}^{\mathrm{V} 600 \mathrm{E}}$ mutation covers over $90 \%$ of the BRAF mutations [11-13]. These mutations activate the MAPK pathway, further triggering aberrant cell proliferation, inhibiting apoptosis and thus promoting tumor 
progression $[12,13]$. Since BRAF mutation is frequently observed in melanoma, BRAF inhibitors (BRAFi: dabrafenib, vemurafenib, and encorafenib) are now applied for clinical use, and show drastically higher clinical responses than dacarbazine-based treatments $[13,14]$. However, recurrence due to the acquisition of drug resistance is widely recognized as a limitation of BRAF-targeted therapy $[15,16]$. Although the use of BRAFi in combination with MEK inhibitors (MEKi) has partly solved this problem, resistance to BRAFi/MEKi still occurs. Thus, alternative or supportive treatments are eagerly anticipated.

Nectin cell adhesion molecule 4 (NECTIN4), a single-pass type I immunoglobulinlike membrane protein that mainly localizes in adherens junctions $[17,18]$, belongs to the nectin family, which mediates various cell functions such as proliferation, differentiation, migration, and invasion [19-21]. NECTIN4 is overexpressed in many types of human cancers, such as urothelial cancer, and its abnormal expression is associated with tumor progression by increasing proliferation and angiogenesis, and decreasing apoptosis [22-24]. These suggest that NECTIN4 is a potential therapeutic target. Indeed, enfortumab vedotin, a kind of antibody-drug conjugates (ADCs) which targets NECTIN4, has been reported to suppress NECTIN4-overexpressing tumor cell growth and further evaluated preclinically in human breast, bladder, pancreas, lung, and urothelial cancers [24-27]. Moreover, several clinical trials are ongoing for evaluating its effects on patients with urothelial cancers expressing high NECTIN4 [28,29]. Thus, NECTIN4-targeted therapy may serve as a potent strategy for treating cancers with high NECTIN4 expression. In skin tissue, NECTIN4 is enriched in epidermal keratinocytes and skin appendages [30-32]. However, the association between NECTIN4 expression and the progression of melanoma and its function in melanoma is largely unknown.

To investigate the NECTIN4 expression in melanoma, we first assessed NECTIN4 in melanoma patients. NECTIN4 was highly expressed in $\mathrm{BRAF}^{\mathrm{V} 600 \mathrm{E}}$-mutated melanoma, and its high expression was associated with poor prognosis. We further showed that NECTIN4 was upregulated in BRAFi-resistant melanoma cells compared with their BRAFisensitive counterparts. This work uncovers a link between NECTIN4 expression with $\mathrm{BRAF}^{\mathrm{V} 600 \mathrm{E}}$ mutation and with BRAFi resistance in melanoma, and provides a rationale for using NECTIN4-targeted drugs to treat melanoma with high NECTIN4.

\section{Results}

\subsection{Characteristics of the Study Cohort}

Comprehensive demographic and clinical data of 126 patients with primary malignant melanoma are shown in Table 1. The mean age was 63.7 years (range: $16-88$ ) and $43.7 \%$ were male and $56.3 \%$ were female. The primary tumor site was predominantly acral areas (hand; 19.8\%, foot; 58.7\%), and the major histopathological subtype was acral lentiginous melanoma (74.6\%). Ulceration was found in $41.3 \%$. The proportion of VE1-positive cases was $30.2 \%$. 
Table 1. Basic demographic and clinical characteristic data of all 126 patients with primary malignant melanoma.

\begin{tabular}{|c|c|c|}
\hline \multicolumn{2}{|c|}{ Parameters } & \multirow{4}{*}{$\begin{array}{c}\text { Number } \\
63.7 \\
69 \\
16-88\end{array}$} \\
\hline & Mean & \\
\hline Age & Median & \\
\hline & Range & \\
\hline \multirow{2}{*}{ Sex } & Male & $55(43.7 \%)$ \\
\hline & Female & $71(56.3 \%)$ \\
\hline \multirow{6}{*}{ Tumor site } & Head and neck & $12(9.5 \%)$ \\
\hline & Trunk & $5(4.0 \%)$ \\
\hline & Upper limb & $3(2.4 \%)$ \\
\hline & Hand & $25(19.8 \%)$ \\
\hline & Lower limb & $7(5.6 \%)$ \\
\hline & Foot & $74(58.7 \%)$ \\
\hline \multirow{4}{*}{ Histopathological subtype } & ALM & $94(74.6 \%)$ \\
\hline & SSM & $15(11.9 \%)$ \\
\hline & LLM & $10(7.9 \%)$ \\
\hline & NM & $7(5.6 \%)$ \\
\hline \multirow{3}{*}{ Ulceration } & Present & $52(41.3 \%)$ \\
\hline & Absent & $70(55.6 \%)$ \\
\hline & Unknown & $4(3.2 \%)$ \\
\hline \multirow{6}{*}{$\mathrm{T}$ category } & Tis & $29(23.0 \%)$ \\
\hline & $\mathrm{T} 1$ & $20(15.9 \%)$ \\
\hline & $\mathrm{T} 2$ & $13(10.3 \%)$ \\
\hline & $\mathrm{T} 3$ & $21(16.7 \%)$ \\
\hline & $\mathrm{T} 4$ & $41(32.5 \%)$ \\
\hline & Unknown & $2(1.6 \%)$ \\
\hline \multirow{5}{*}{$\mathrm{N}$ category } & No & $85(67.5 \%)$ \\
\hline & N1 & $15(11.9 \%)$ \\
\hline & N2 & $11(8.7 \%)$ \\
\hline & N3 & $14(11.1 \%)$ \\
\hline & Unknown & $1(0.8 \%)$ \\
\hline \multirow{2}{*}{ M category } & M0 & $115(91.3 \%)$ \\
\hline & M1 & $11(8.7 \%)$ \\
\hline \multirow{2}{*}{ VE1 staining } & Positive & $38(30.2 \%)$ \\
\hline & Negative & $88(69.8 \%)$ \\
\hline
\end{tabular}

Data are presented as $n(\%)$. ALM, acral lentiginous melanoma; SSM, superficial spreading melanoma; NM, nodular melanoma; LLM, lentigo malignant melanoma.

\subsection{Association of NECTIN4 with Clinicopathological Factors and Prognostic Impact in Melanoma}

As expected, NECTIN4 was observed in the epidermis (in the cytoplasm and on the membrane) (Figure 1a). SOX10, a melanoma specific marker, was stained simultaneously to distinguish melanoma cells. Importantly, NECTIN4 was expressed in melanomas and co-expressed with SOX10 (Supplementary Figure S1). Then, NECTIN4 expression in melanoma patients was examined and presented as the H-score (mean: 48.1, range: 0-225, median: 30, Supplementary Figure S2) [33]. Samples were divided into two groups by the mean H-score: NECTIN4-low (H-score $\leq 48.1)$ and NECTIN4-high (H-score > 48.1). The associations between immunohistochemical NECTIN4 expression and clinicopathological factors was analyzed. NECTIN4 was high in 35.7\% and low in $64.3 \%$ patients. Among the factors analyzed, only VE1 staining, which indicates the presence of $\mathrm{BRAF}^{\mathrm{V} 600 \mathrm{E}}$ mutation, was significantly positively associated with NECTIN4 $(p=0.0011$, Table 2$)$. Of note, patients with NECTIN4-high melanoma showed significantly poor disease-free survival (DFS) compared with those with NECTIN4-low melanoma $(p=0.0358)$ (Figure 1b). 
As for melanoma-specific survival (MSS) and overall survival (OS), NECTIN4-high patients tended to show shortened survival ( $p=0.196$ for MSS and $p=0.0733$ for OS) (Figure 1c,d).

a
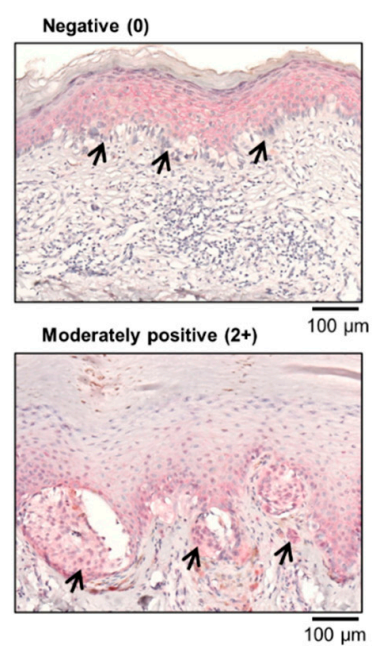

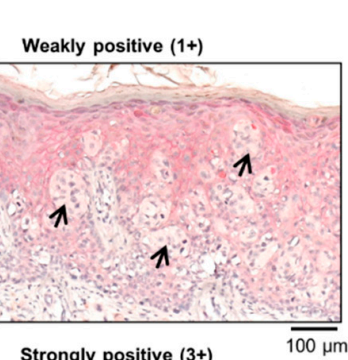

Strongly positive (3+)

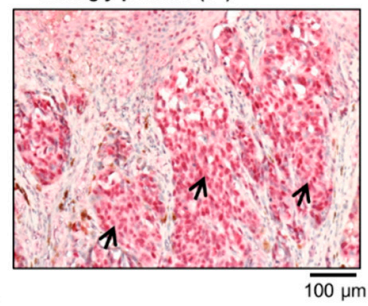

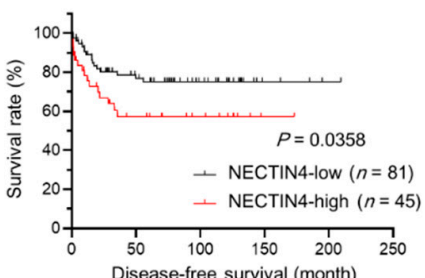
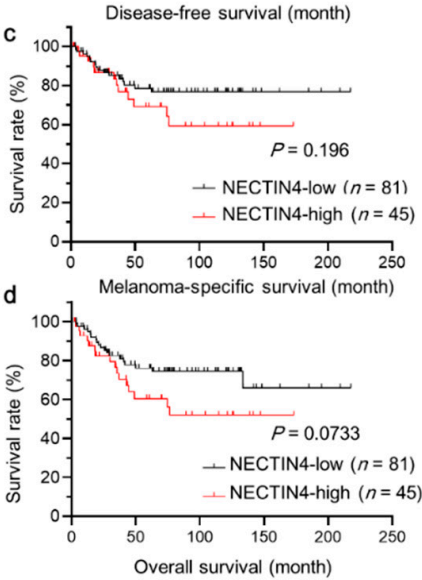

Figure 1. NECTIN4 is expressed in melanoma tissues and is associated with BRAF mutation. Immunohistochemical staining of NECTIN4 in a patient's tumor tissue. (a) Representative images from 126 melanoma samples are shown. The intensity of the staining was classified on a scale from 0 to $3+$ : no staining (0), weakly positive (1+), moderately positive (2+), and strongly positive (3+). Black arrows indicate NECTIN4-positive cells. Scale bar $=100 \mu \mathrm{m}$. (b-d) Survival curve of NECTIN4 expression intensity and (b) disease-free survival, (c) melanoma-specific survival, and (d) overall survival $(n=126)$. Patients' survival was calculated using the Kaplan-Meier method and the log-rank test. $p<0.05$ was considered to indicate a statistically significant difference.

Table 2. Factors associated with NECTIN4 expression.

\begin{tabular}{|c|c|c|c|c|}
\hline \multirow{2}{*}{ Parameter } & & \multicolumn{2}{|c|}{ NECTIN4 Expression } & \multirow{2}{*}{$p$-Value } \\
\hline & & Low & High & \\
\hline \multirow{2}{*}{ Age } & $<70$ & 46 & 25 & \multirow{2}{*}{$>0.999$} \\
\hline & $\geq 70$ & 35 & 20 & \\
\hline \multirow{2}{*}{ Sex } & Male & 35 & 20 & \multirow{2}{*}{$>0.999$} \\
\hline & Female & 46 & 25 & \\
\hline \multirow{2}{*}{ Histopathological subtype } & ALM & 62 & 32 & \multirow{2}{*}{0.527} \\
\hline & Others & 19 & 13 & \\
\hline \multirow{2}{*}{ Ulceration } & Present & 33 & 19 & \multirow{2}{*}{0.849} \\
\hline & Absent & 46 & 24 & \\
\hline \multirow{2}{*}{$\mathrm{T}$ category } & Tis, T1, T2 & 39 & 20 & \multirow{2}{*}{$>0.999$} \\
\hline & T3, T4 & 42 & 23 & \\
\hline \multirow{2}{*}{ N category } & N0 & 55 & 30 & \multirow{2}{*}{0.843} \\
\hline & N1-3 & 25 & 15 & \\
\hline \multirow{2}{*}{ M category } & M0 & 74 & 41 & \multirow{2}{*}{$>0.999$} \\
\hline & M1 & 7 & 4 & \\
\hline \multirow{2}{*}{ VE1 staining } & Positive & 16 & 22 & \multirow{2}{*}{0.0011 * } \\
\hline & Negative & 65 & 23 & \\
\hline
\end{tabular}

Data are presented as $n(\%) .{ }^{*} p<0.05$ indicated statistical significance determined by the multivariate Cox proportional hazards regression analysis. ALM, acral lentiginous melanoma. 


\subsection{NECTIN4 Is Upregulated in BRAFi-Resistant Melanoma Cells}

We next investigated the association between NECTIN4 and BRAF mutation. The intensity of NECTIN4 was positively correlated with VE1 staining (Table 2, $p=0.0011$ ). This implies that NECTIN4 might be involved in malignant transformation and drugresistance development in $\mathrm{BRAF}^{\mathrm{V} 600 \mathrm{E}}$-melanomas. We then generated dabrafenib (a widely used BRAFi)-resistant (DR) melanoma cells in MEL1617 and SKMEL28 melanoma cell lines using a stepwise selection by increasing concentration of dabrafenib. Most MEL1617 melanoma cells originally presented a polygonal or stellate shape, whereas MEL1617DR cells showed a flatter and epithelial-like shape (Figure 2a). Although the growth of MEL1617 cells was strongly inhibited by dabrafenib, MEL1617-DR cells could proliferate even in the presence of dabrafenib (Figure 2b). Similar results were obtained in SKMEL28 and SKMEL28-DR cell lines (Figure 2c,d). Besides, activation of EGFR and MEK/ERK signal, which are the well-known factors of BRAFi-resistance [34-37], was observed in MEL1617-DR and SKMEL28-DR cell lines (Supplementary Figure S3). These results confirmed that MEL1617-DR and SKMEL28-DR cell lines have acquired drug resistance to dabrafenib. Next, the NECTIN4 expression was examined. NECTIN4 was expressed in these melanoma cells in both mRNA and protein levels (Figure 2e,f). NECTIN4 was significantly increased in MEL1617-DR and SKMEL28-DR compared with their drugsensitive counterparts. These results show that NECTIN4 is expressed in melanoma cells and that its expression is upregulated in BRAFi-resistant cells.

Since NECTIN4 is expressed in melanoma cells, we next examined whether these NECTIN4-expressing melanoma cells are sensitive to MMAE, a cytotoxic part of enfortumab vedotin. The concentration of MMAE in patients' peripheral blood is $2.6-5.0 \mathrm{ng} / \mathrm{mL}$ [38] The cells were treated with various concentrations of MMAE and 1.25 nM of MMAE was enough to suppress cell growth at $48 \mathrm{~h}$ after treatment in all melanoma cell lines (Figure 2g,h). Considering the NECTIN4 expression in melanoma cells and their sensitivity to MMAE, enfortumab vedotin may act as an effective anti-tumor drug against melanoma, and BRAFi-resistant cells are more likely to be sensitive to it.

\subsection{Akt Phosphorylation Is Enhanced in BRAFi-Resistant Melanoma Cells}

NECTIN4 is known to activate the PI3K/Akt pathway, which regulates tumor cell proliferation and tumor growth $[39,40]$. Since NECTIN4 was upregulated in the BRAFiresistant cells, we next investigated whether the PI3K/Akt pathway is also activated or not. The phosphorylation status of Akt, a downstream molecule of the PI3K, was assessed, and it was significantly upregulated in MEL1617-DR and SKMEL28-DR compared with their drug-sensitive counterparts (Figure 3a,b). Thus, the PI3K/Akt pathway is activated in these BRAFi-resistant cells, implying an interaction between NECTIN4 upregulation and PI3K activation in BRAFi resistance.

\subsection{Knockdown of NECTIN4 Impairs PI3K/Akt Pathway and Increases Apoptosis of Melanoma Cells}

To investigate the relationship between NECTIN4 and PI3K/Akt activation, we inhibited NECTIN4 and examined whether it alters the Akt phosphorylation. NECTIN4 was significantly downregulated by siRNA in all cell lines (Figure 3c,d). The Akt phosphorylation was significantly reduced by NECTIN4 knockdown in all cell lines compared with that in control siRNA-transfected cells (Figure 3e,f). These results indicate that NECTIN4 is involved in the PI3K/Akt activation in melanoma cells.

$\mathrm{PI} 3 \mathrm{~K} / \mathrm{Akt}$ pathway activation increases the proliferation of cancer cells and prevents apoptosis. Since NECTIN4 and phosphorylated Akt were both increased in the BRAFiresistant cells and NECTIN4 inhibition reduced the phosphorylated Akt, we speculated that NECTIN4 expression and the subsequent PI3K/Akt pathway activation may decrease the apoptosis of the cells. Then, we evaluated the apoptotic cells by the Annexin Vpropidium iodide (PI) staining in NECTIN4-inhibited cells (Figure 4). The percentages of the Annexin V-positive PI-positive (late apoptotic) cells and Annexin V-positive PI-negative 
(early apoptotic) cells among the total cells were analyzed at $48 \mathrm{~h}$ after siRNA transfection (Figure 4a). The percentage of total apoptotic cells (late and early) was significantly increased in the NECTIN4-knockdown MEL1617 $(p=0.0318)$ and NECTIN4-knockdown MEL1617-DR ( $p=0.0381$ ) compared with control siRNA-treated condition (Figure $4 \mathrm{~b}$ ). The percentage of total apoptotic cells was also significantly increased in the NECTIN4knockdown SKMEL28 $(p=0.00412)$ and NECTIN4-knockdown SKMEL28-DR $(p=0.00698)$ compared with control siRNA-treated condition (Figure 4c). These results indicate that NECTIN4 may be partially responsible for the regulation of apoptosis in melanoma cells.
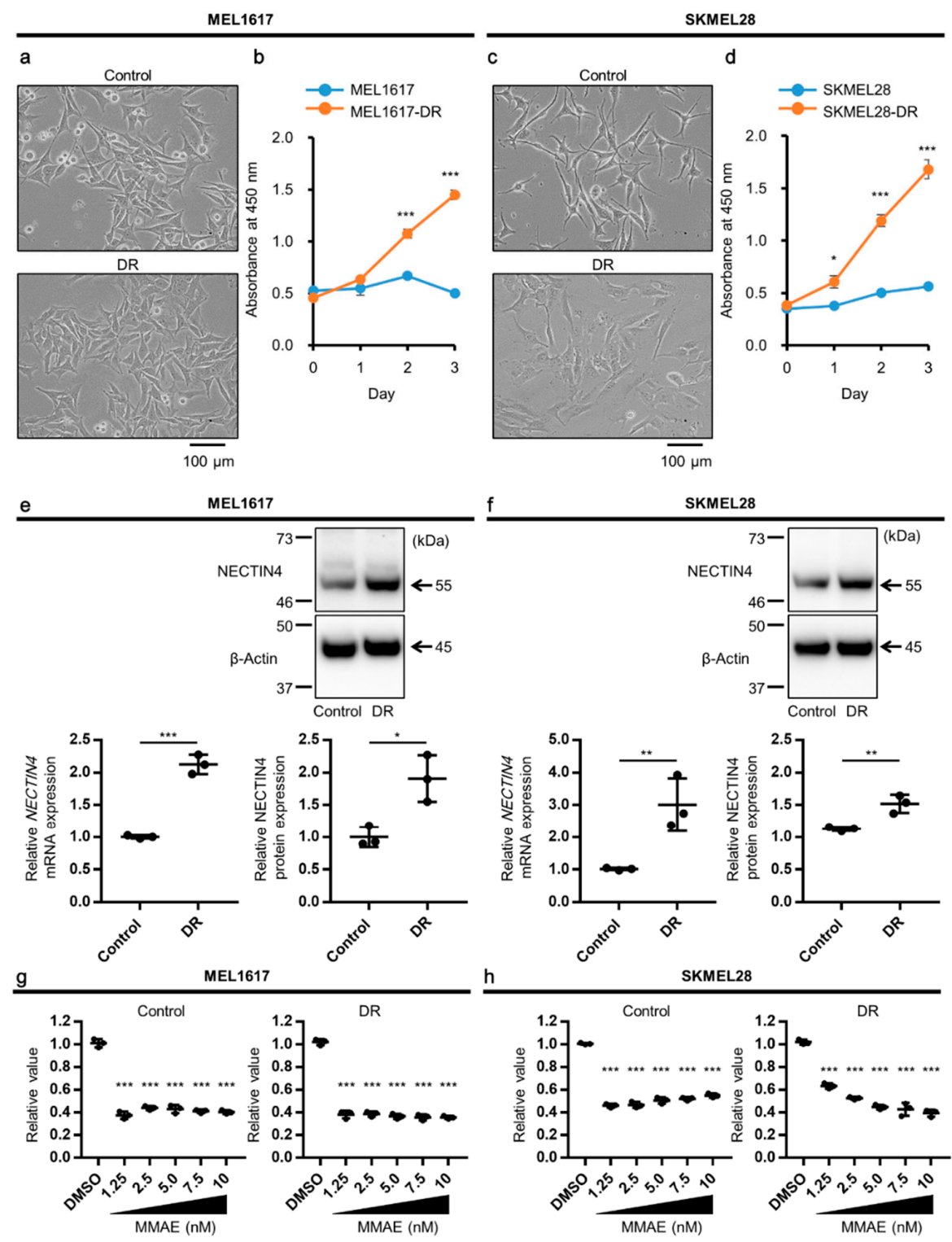

Figure 2. BRAFi-resistant melanoma cells highly express NECTIN4 and are sensitive to MMAE. (a) Representative images of MEL1617 (Control) and its dabrafenib-resistant (DR) cells. Scale bar $=100 \mu \mathrm{m}$. (b) Growth curve of MEL1617 and MEL1617DR treated with $1 \mu \mathrm{M}$ dabrafenib. (c) Representative images of SKMEL28 (Control) and its DR cell lines. Scale bar $=100 \mu \mathrm{m}$. (d) Growth curve of SKMEL28 and SKMEL28-DR treated with $1 \mu \mathrm{M}$ dabrafenib. (e,f) The expression of NECTIN4 mRNA and NECTIN4 protein in (e) MEL1617 and (f) SKMEL28 and their DR cell lines $(n=3)$. Representative gel images of NECTIN4 and $\beta$-Actin (a loading control) are shown. (g) MEL1617 and (h) SKMEL28, and their DR cell lines were treated with DMSO $(0.1 \%)$ or MMAE $(1.25,2.5,5,7.5$, or $10 \mathrm{nM})$ for $48 \mathrm{~h}$ and assessed for cell viability $(n=3)$. Data are presented as the mean \pm standard deviation of three independent experiments. ${ }^{*} p<0.05$, ${ }^{* *} p<0.01$, and ${ }^{* *} p<0.001$ determined by Student's unpaired two-tailed $t$-test. 


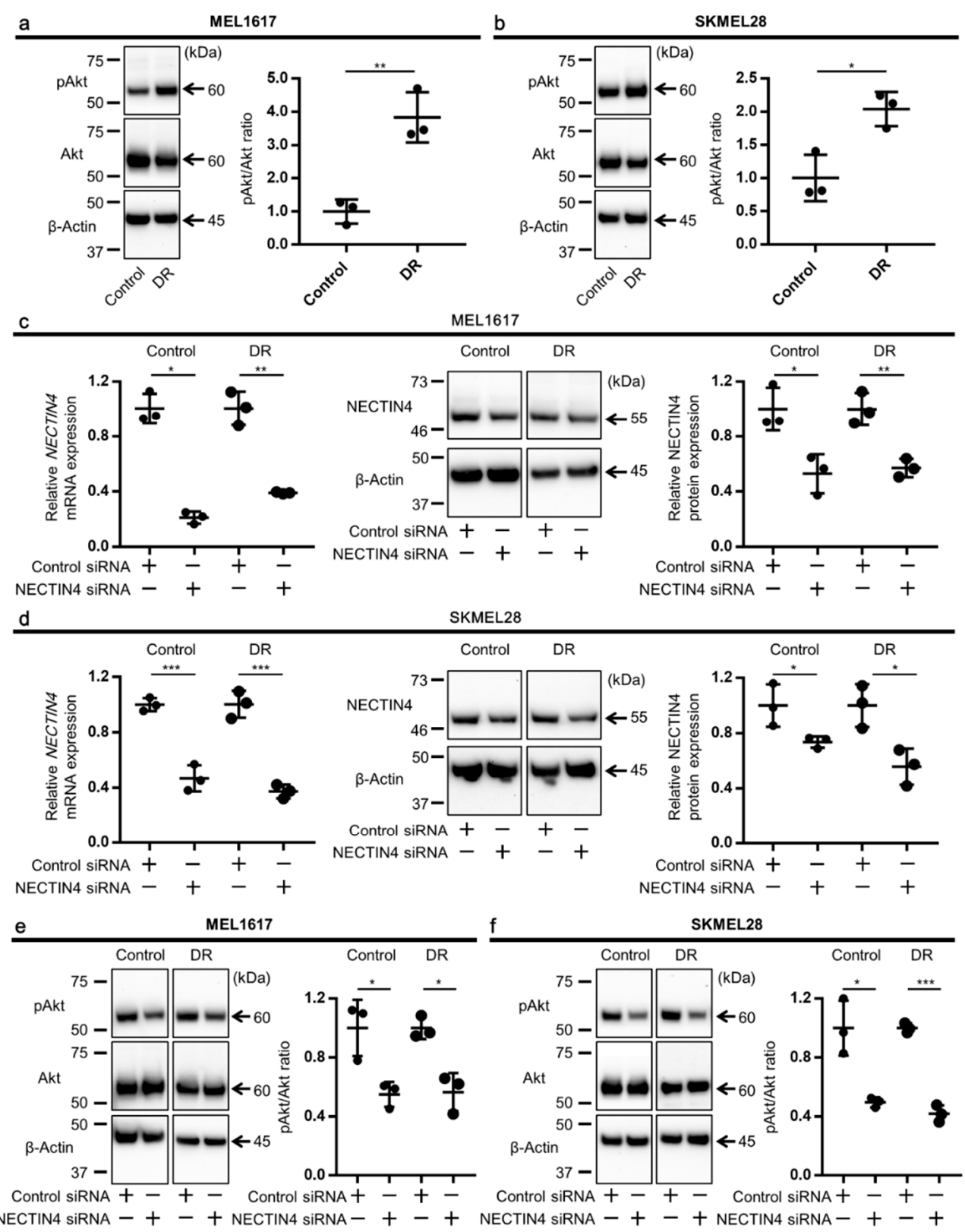

Figure 3. Phosphorylation of Akt is upregulated in BRAFi-resistant melanoma cells which are inhibited by NECTIN4 silencing. The pAkt/Akt ratio was determined by Western blotting. Representative gel images and relative pAkt/Akt ratios in (a) MEL1617 and (b) SKMEL28, and their DR cell lines are shown $(n=3)$. Cells were transfected with control or NECTIN4 siRNA for $48 \mathrm{~h}$. Knockdown efficiency of NECTIN4 at mRNA (left panels) and at protein (middle and right panels) in (c) MEL1617 and (d) SKMEL28, and their DR cell lines are shown. pAkt/Akt ratio in (e) MEL1617 and (f) SKMEL28, and their DR cell lines transfected with NECTIN4 siRNA for $48 \mathrm{~h}$. Representative gel images and the pAkt/Akt ratio relative to that of control siRNA-treated samples are shown $(n=3)$. Data are presented as the mean \pm standard deviation of three independent experiments. $\beta$-Actin served as a loading control. ${ }^{*} p<0.05,{ }^{* *} p<0.01$, and ${ }^{* * *} p<0.001$ determined by Student's unpaired two-tailed $t$-test. 
a

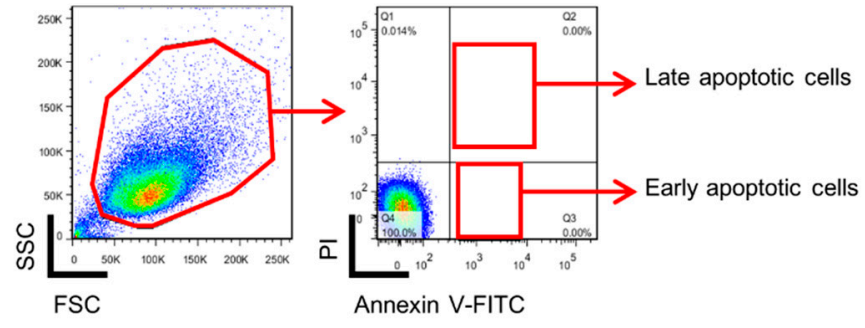

b

MEL1617
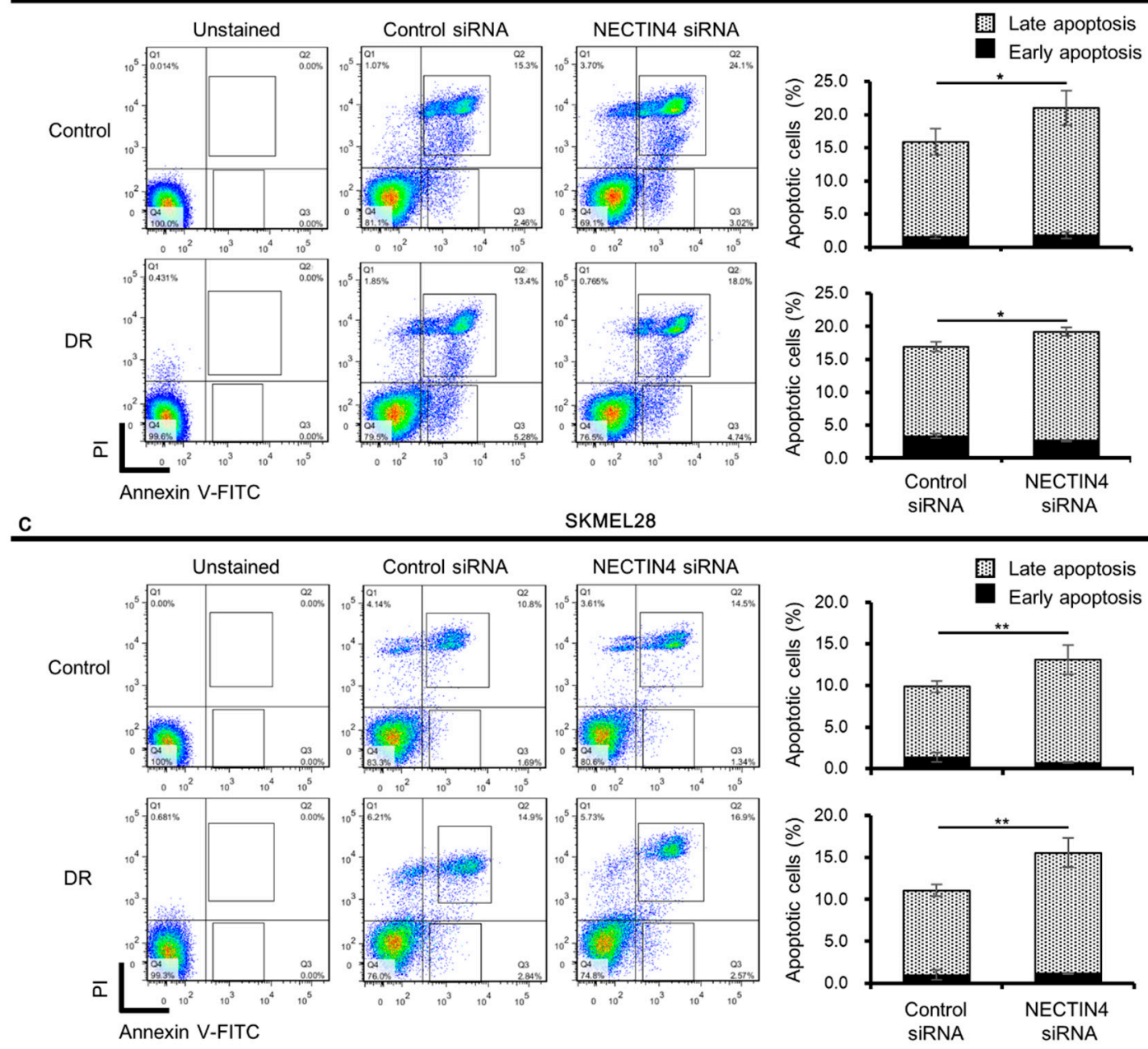

Figure 4. NECTIN4 is involved in the regulation of apoptosis in BRAFi-resistant melanoma cells. (a) Gating strategy of flow cytometric analysis. Non-specific signals were removed by the first gate. The gated fraction was further expanded with Annexin V-FITC and PI, and analyzed for the percentage of late (Annexin V-positive PI-positive) and early (Annexin Vpositive PI-negative) apoptotic cells. Representative flow cytometric images (left panels) and the percentage of apoptotic cells among all cells (right panels) of (b) MEL1617 and (c) SKMEL28, and their DR cell lines are shown $(n=3)$. Data are presented as the mean \pm standard deviation of three independent experiments. ${ }^{*} p<0.05$ and ${ }^{* *} p<0.01$ determined by Student's unpaired two-tailed $t$-test.

\subsection{PI3K/Akt and NECTIN4 Inhibition Improved the Sensitivity of Melanoma Cells to BRAFi}

To investigate whether the inhibition of the PI3K/Akt pathway improved the sensitivity of melanoma cells to the BRAFi, cells were treated with LY294002, a PI3K inhibitor, in combination with dabrafenib and assessed for the cell viability. The inhibition of PI3K/Akt by LY294002 was confirmed by analyzing the pAkt/Akt ratio. At 48-72 h after LY294002 treatment, phosphorylation of Akt was significantly inhibited in all of the cell lines tested (Supplementary Figure S4). The proliferation of MEL1617 was originally inhib- 
ited by dabrafenib and the additional treatment with LY294002 further suppressed the cell proliferation. MEL1617-DR, which proliferated in the presence of dabrafenib, showed significantly suppressed proliferation upon PI3K/Akt inhibition (Figure 5a). SKMEL28 and SKMEL28-DR showed similar results, LY294002 treatment significantly suppressed the proliferation of both cell lines when treated with dabrafenib (Figure 5b).

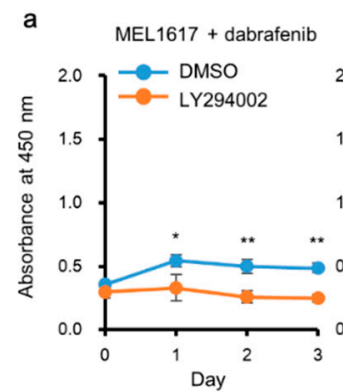

C

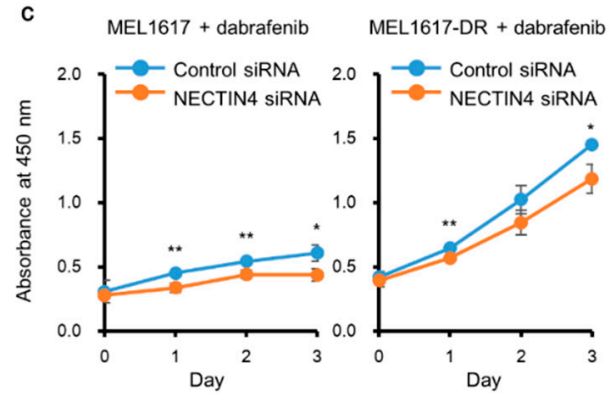

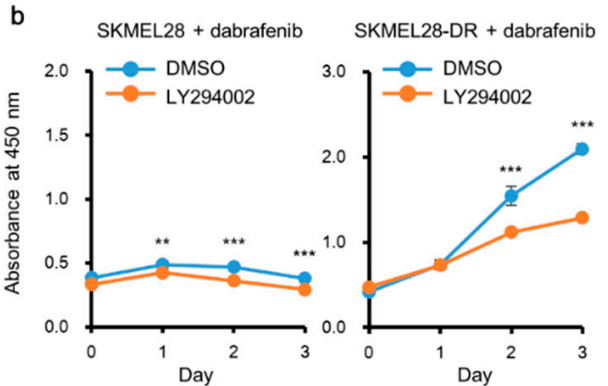

d SKMEL28 + dabrafenib SKMEL28-DR + dabrafenib

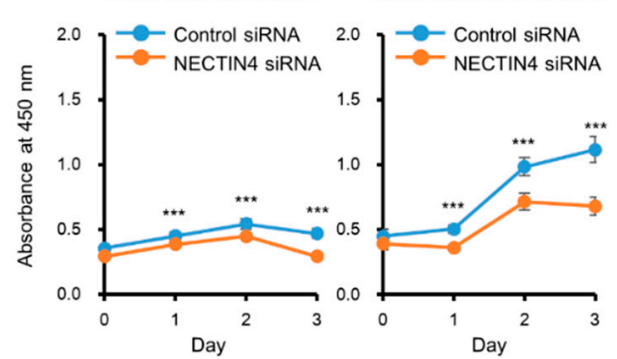

Figure 5. NECTIN4 inhibition increases sensitivity of BRAFi-resistant melanoma cells to BRAFi. (a) MEL1617 and (b) SKMEL28, and their DR cell lines were treated with DMSO (0.1\%) or PI3K inhibitor LY294002 (10 $\mu$ M) with dabrafenib for 3 days. (c) MEL1617 and (d) SKMEL28, and their DR cell lines were transfected with control or NECTIN4 siRNA in the presence of dabrafenib for 3 days. Viable cells in each condition were detected using Cell Counting Kit-8 (CCK8). Experiments were performed in triplicate wells and repeated three times $(n=9)$. Data are presented as the mean \pm standard deviation. ${ }^{*} p<0.05,{ }^{* *} p<0.01$, and ${ }^{* * *} p<0.001$ determined by Student's unpaired two-tailed $t$-test.

Next, the effects of NECTIN4 inhibition on the sensitivity of melanoma cells to BRAFi were examined. NECTIN4 expression and the phosphorylation of Akt were both significantly decreased by siRNA in all cell lines (Supplementary Figures S5 and S6). In the MEL1617 and the MEL1617-DR cultured with dabrafenib, NECTIN4 inhibition slightly but significantly inhibited the proliferation of the cells compared with that of control siRNAtreated cells (Figure 5c). In the SKMEL28 and the SKMEL28-DR cultured with dabrafenib, NECTIN4 inhibition significantly inhibited the proliferation of the cells compared with that of control siRNA-treated cells (Figure $5 \mathrm{~d}$ ).

Taking all results together, the NECTIN4 induction and the subsequent PI3K/Akt pathway activation may cause BRAFi resistance and promote melanoma cell proliferation, suggesting that NECTIN4-targeted therapy may serve as a potent treatment for patients with BRAFi-resistant melanoma.

\subsection{NECTIN4 Inhibition Down-Regulated ERK Signal in BRAFi-Resistant Melanoma Cells}

The activation of MEK/ERK signal is a well-known feature of BRAFi-resistance [34-37], and it was observed in our BRAFi-resistant cell lines as well (Supplementary Figure S3). To obtain further insight into the relationship of NECTIN4 and BRAFi resistance, the status of the MEK/ERK pathway was assessed in NECTIN4-inhibited BRAFi-resistant melanoma cell lines. The phosphorylated ERK, but not phosphorylated MEK, was significantly decreased in NECTIN4-inhibited cells compared to control siRNA-transfected cells in both MEL1617-DR and SKMEL28-DR cell lines (Figure 6). These results imply 
that NECTIN4 partly contributes to the drug-resistance of these melanoma cell lines by affecting ERK signaling.
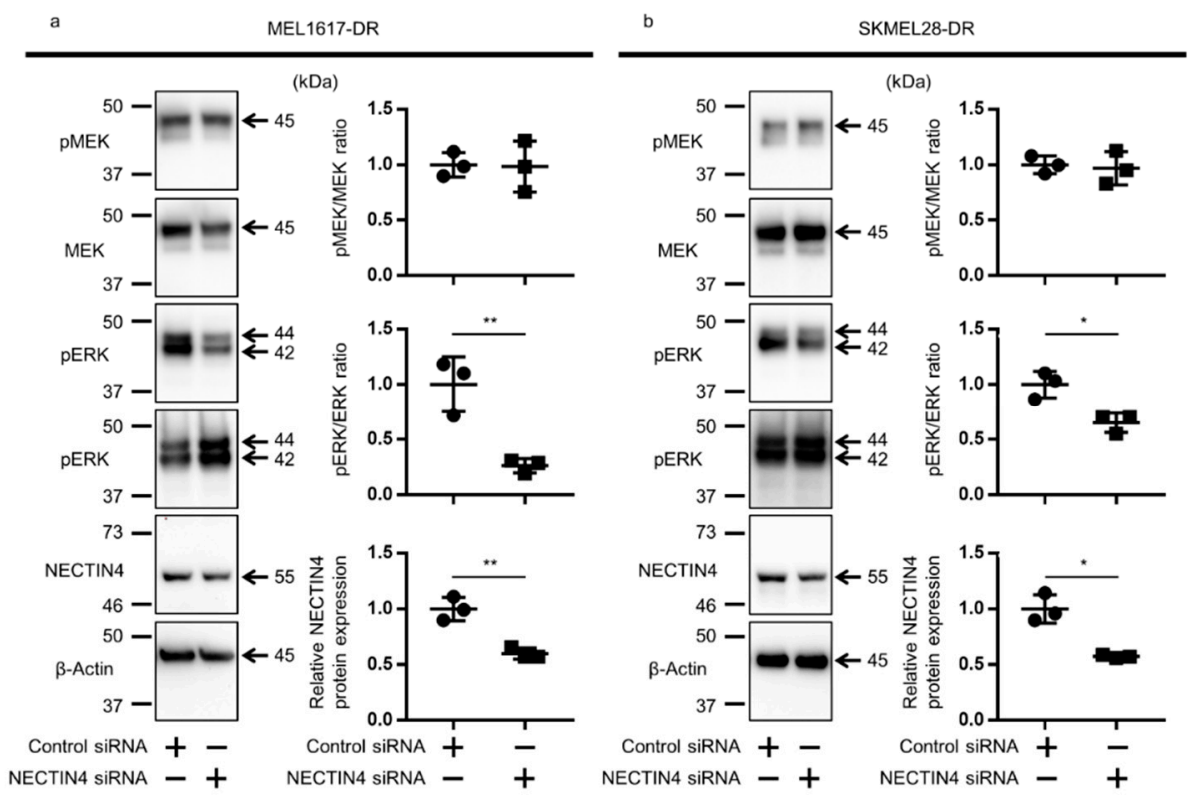

Figure 6. NECTIN4 inhibition downregulates phosphorylated ERK in MEL1617-DR and SKMEL28DR cell lines. (a) MEL1617-DR and (b) SKMEL28-DR cell lines were transfected with control or NECTIN4 siRNA and assessed for pMEK/MEK and pERK/ERK ratio. Representative blot images (left panels), and pMEK/MEK ratio, pERK/ERK ratio, and relative NECTIN4 expression (right panels, $n=3)$ are shown. Data are presented as the mean \pm standard deviation of three independent experiments. $\beta$-Actin served as a loading control. ${ }^{*} p<0.05$ and ${ }^{* *} p<0.01$ determined by Student's unpaired two-tailed $t$-test.

\section{Discussion}

In this paper, we report for the first time that NECTIN4 is expressed in human melanoma, with an especially higher frequency in BRAF-mutated melanoma. Immunohistochemically, high NECTIN4 expression was associated with worse prognosis of the patients. In vitro analyses revealed increased NECTIN4 in the BRAFi-resistant melanoma cells and upregulation of the PI3K/Akt pathway. Knockdown of NECTIN4 induced apoptosis and improved sensitivity to BRAFi, suggesting the roles of NECTIN4 in the survival of BRAFi-resistant melanomas.

The expression of NECTIN4 is generally low in normal tissues, whereas it increases in various malignant tumors; its association with tumor progression has been reported among breast, urothelial, pancreatic, lung, and ovarian cancers [22-24]. Patients with NECTIN4-high tumors had significantly poorer overall survival than those with low ones in pancreatic cancer [22]. In addition, NECTIN4 expression was reported to be positively correlated with Ki67 and the silencing of NECTIN4 inhibited the proliferation of human pancreatic cancer cells, implying its role in the proliferation of tumor cells [22]. The involvement of NECTIN4 in tumor progression has been reported in other tumors as well, including gallbladder, breast, gastric, and papillary thyroid cancers [39-42]. In normal skin, NECTIN4 is mainly expressed in the epidermal keratinocytes and skin appendages [30-32]; however, its expression in skin cancers has not been extensively investigated. In agreement with reports on other tumors, we found that NECTIN4 is expressed in melanoma and its expression reflects a poorer prognosis. We also showed that the silencing of NECTIN4 resulted in the reduction in the proliferation and induction of apoptosis in melanoma cells. Mutational activation of BRAF is associated with tumor progression and BRAF-mutated melanoma showed higher NECTIN4 expression than melanoma with wild-type BRAF. 
In the current study, we found that high NECTIN4 expression was significantly associated with worse DFS, but not with MSS and OS. In general, MSS and OS is influenced by the systemic treatments after metastasis, while DFS may reflect the primary tumor characteristics more accurately. BRAF-mutated melanoma can be treated with BRAFi and is more sensitive to ICI than BRAF-wild-type melanoma. Indeed, 13 patients in our cohort were treated with BRAFi and/or ICI; these treatments might have led to the failure to find a significant correlation with MSS and OS. NECTIN4 is likely to be associated with the tumor prognosis and plays roles in the progression of melanoma.

Regarding the mechanisms underlying NECTIN4-mediated tumor progression, previous reports demonstrated the involvement of the PI3K/Akt pathway in multiple cancers [39-42]. Higher NECTIN4 expression was associated with poorer prognosis of gastric cancer and papillary thyroid cancer, and the progression of cancer was promoted by NECTIN4 via activation of the PI3K/Akt pathway [41,42]. In addition to the PI3K/Akt pathway, BRAF and its downstream MEK/ERK pathway regulates the growth of melanoma cells [34]. However, a study on gallbladder cancer failed to show the involvement of the MEK/ERK pathway in the oncogenic function of NECTIN4, despite the positive correlation of the PI3K/Akt pathway [39]. Consistent with these reports, our results showed that the PI3K/Akt signaling was activated in BRAFi-resistant melanoma cells, where NECTIN4 levels were increased. Silencing of NECTIN4 resulted in the inhibition of the PI3K/Akt pathway, followed by decreased proliferation and increased apoptosis. The inhibition of PI3K/Akt by LY294002 also prevented the proliferation of the cells and improved drug sensitivity. Taking these findings together, NECTIN4 is suggested to play roles in the progression of melanoma, presumably through activation of the PI3K/Akt signaling pathway.

In this report, we used two drug-resistant cell lines and drug-resistant SKMEL28 cells seemed to be more susceptible to the treatments than drug-resistant MEL1617 cells. Although these cell lines are both derived from cutaneous melanoma bearing $\mathrm{BRAF}^{\mathrm{V} 600 \mathrm{E}}$ mutation, they are known to have different genetic statuses regarding PTEN, P53, CDKN2A, and CDK4 as reported by Villanueva and colleagues [43]. MEL1617 has wild type PTEN, P53, CDK4, and lacks CDKN2A. On the other hand, SKMEL28 has mutated PTEN and $C D K 4$, wild type $C D K N 2 A$, and lacks $P 53$. To our knowledge, direct relationships between NECTIN4 and PTEN, P53, CDK4, or CDKN2A have not been reported, but differences in these genes may affect the susceptibility of cells to the treatments.

Resistance to BRAFi is a serious concern for the treatment of unresectable melanoma. Although BRAFi improved the survival of patients with BRAF-mutated melanoma, its effect does not last long (a median time to progression of 5.1-8.8 months) [34] due to the acquisition of drug resistance with multiple causes [34-37]. In addition, less than $20 \%$ of patients with BRAF-mutated melanoma present intrinsic resistance and do not respond to BRAFi $[14,36,44]$. To overcome these issues, the combination of BRAFi/MEKi is now used in a clinical setting, and it significantly improved the response rate and duration [34,45]. ICI has also improved the prognosis of melanoma patients [6,7]. These therapies constitute a major change in the treatment of advanced melanoma; however, a subset of patients does not respond or still develops drug resistance [8,9,34]. Novel drugs effective for BRAFi/MEKi-resistant or ICI-resistant melanoma are thus desired. Although the association between BRAFi resistance and NECTIN4 expression has not been reported, we found that the expression of NECTIN4 was increased, along with the acquisition of BRAFi resistance in melanoma cells. In addition, ERK signal activation, one of the mechanisms of BRAFi-resistance acquisition and observed in our DR cell lines, was slightly but significantly inhibited by NECTIN4 knockdown (Figure 6). Although detailed investigation is required, NECTIN4 may partly contribute to the acquisition of drug-resistance and these results imply the potency of NECTIN4 as a target of novel drugs for BRAFi-resistant melanoma.

Taking our findings together, we have shown that 1 NECTIN4 is expressed in melanoma patients and in melanoma cells, 2 NECTIN4 is upregulated in response to the acquisition of BRAFi resistance, and 3 melanoma cells are sensitive to MMAE (an anti-mitotic drug that 
is a component of ADCs). Since the phenotypes and the results observed in this research are based on the short-term culture and reflect transient phenomena, further long-term experiments need to be performed in the future. Even though our results suggest that the NECTIN4-targeting ADCs, such as enfortumab vedotin, exert antitumor effects against melanoma regardless of their BRAF mutation status, even after the melanoma cells develop to acquire BRAFi resistance.

\section{Materials and Methods}

\subsection{Cell Culture}

MEL1617 and SKMEL28 melanoma cell lines (ATCC, Rockville, MD, USA) were cultured in basal media: RPMI1640 (Sigma-Aldrich, St. Louis, MO, USA; R8758) supplemented with 10\% fetal bovine serum (Nichirei Biosciences, Tokyo, Japan; 174012), and 0.1\% DMSO (Sigma-Aldrich; 07-4860-5). DR melanoma cells were maintained in basal media with $1 \mu \mathrm{M}$ dabrafenib (ChemScene, Deerpark, NJ, USA; CS-0692). Cells were passaged at a subconfluent and media were refreshed every 2 days. Cells were used within five passages after thaw and verified for correct morphology by microscopic observation. Cell images were captured with a microscope (Nikon Corporation, Tokyo, Japan; Nikon ECLIPSE TS100).

\subsection{Generation of BRAFi-Resistant Melanoma Cells}

Cells were chronically treated with stepwise increased concentrations of dabrafenib. Cells were selected at each step until they resumed the same growth kinetics as the untreated parental line before moving to the next step. Throughout the 6 weeks of treatment, the dabrafenib concentration was increased from 0.3 to $1.0 \mu \mathrm{M}$. The sensitivity of cells to dabrafenib was assessed using MTS-based cell viability assays.

\subsection{Cell Viability}

Cell viability was determined using Cell Counting Kit-8 (CCK-8, Dojindo, Kumamoto, Japan; 347-07621). Cells were seeded in 96-well plates (2000-5000 cells/well), treated with MMAE (1.25, 2.5, 5.0, 7.5, and $10 \mathrm{nM}$, ChemScene; CS-0837), siRNAs, or an Akt inhibitor LY294002 (10 $\mathrm{MM}$, Abcam, Cambridge, UK; ab120243), and incubated at $37{ }^{\circ} \mathrm{C}$ with $5 \% \mathrm{CO}_{2}$. After $1-3$ days, cells were treated with CCK-8 solution for $2-4 \mathrm{~h}$ and absorbance at $450 \mathrm{~nm}$ was measured using an iMark microplate reader (Bio-Rad Laboratories, Hercules, CA, USA; 1681130J1).

\section{4. siRNA Transfection}

Cells were transfected with control siRNA (Invitrogen, Carlsbad, CA, USA; AM4611) or NECTIN4 siRNA (Invitrogen; s37689) using Lipofectamine RNAiMAX (Invitrogen; 13778075). Briefly, siRNAs were diluted with Opti-MEM ${ }^{\mathrm{TM}}$ I Reduced Serum Medium (Thermo Fisher Scientific, Waltham, MA, USA; 31985062), mixed with Lipofectamine, and incubated for $20 \mathrm{~min}$ at room temperature. Then, the siRNA-Lipofectamine complexes were mixed with the cells (final siRNA concentration of $10 \mathrm{nM}$ ). At $24-72 \mathrm{~h}$ after transfection, the cells were harvested and used for further analysis. The knockdown efficiency was determined by quantitative reverse-transcription polymerase chain reaction (qRT-PCR) and Western blotting.

\subsection{RNA Extraction and $q R T-P C R$}

RNA was extracted using RNeasy Mini Kit (Qiagen, Hilden, Germany; 74014), converted to cDNA by PrimeScript RT Reagent Kit (Takara Bio Inc., Kusatsu, Japan; RR037), and used for PCR with TB Green Premix ExTaq (Takara Bio Inc.; RR420) and CFX Connect ${ }^{\mathrm{TM}}$ Real-Time System (Bio-Rad Laboratories; 1855201J1). The sequences of primers were as follows: NECTIN4 forward; 5'-CAAAATCTGTGGCACATTGG-3' ${ }^{\prime}$, reverse; $5^{\prime}$-GCTGACATGG CAGACGTAGA- $3^{\prime}$, and $\beta$-Actin (ACTB, an internal control gene) forward; $5^{\prime}$-ATTGCCGAC AGGATGCAGA- ${ }^{\prime}$, reverse; $5^{\prime}$-GAGTACTTGCGCTCAGGAGGA- $3^{\prime}$. The expression of each mRNA relative to that of control samples was calculated by the comparative $\mathrm{Ct}$ method. 


\subsection{Western Blotting}

Western blotting was performed as reported previously [46]. The antibodies used were as follows: rabbit anti-human NECTIN4 (1:1000, Abcam; ab192033), rabbit anti-human Akt (1:1000, \#9272), rabbit anti-human phospho-Akt (1:2000, \#4060), rabbit anti-human ERK (1:1000, \#9102), rabbit anti-human phospho-ERK (1:2000, \#4370), rabbit anti-human MEK (1:1000, \#9122), rabbit anti-human phospho-MEK (1:1000, \#9154), rabbit anti-human EGFR (1:1000, \#4267), rabbit anti-human $\beta$-actin (1:2000, \#4970), and goat anti-rabbit IgG horseradish peroxidase-linked secondary antibody (1:10,000, \#7074) (all from Cell Signaling Technologies, Danvers, MA, USA). Immunological bands were visualized with SuperSignal ${ }^{\mathrm{TM}}$ West Pico Chemiluminescence Substrate (Thermo Fisher Scientific; 34580) and captured with the ChemiDoc ${ }^{\mathrm{TM}}$ XRS Plus System (Bio-Rad Laboratories; 1708265J1PC). The signals of bands were measured with Image Lab Software (Bio-Rad Laboratories).

\subsection{Annexin V-PI Staining and Flow Cytometry}

Cells were seeded in 6-well plates and transfected with siRNAs as mentioned above. At $48 \mathrm{~h}$, cells were harvested by pipetting and labeled with Annexin V-FITC and PI in accordance with the instructions of the Annexin V-FITC Apoptosis Detection Kit (Nacalai Tesque, Kyoto, Japan; 15342-54). Apoptotic cells were detected with a FACSCanto II flow cytometer (BD Biosciences, Franklin Lakes, NJ, USA) and analyzed with FlowJo software (Tree Star, San Carlos, CA, USA).

\subsection{Patients}

This study is a retrospective review of our patients and conducted in accordance with the guidelines of the Declaration of Helsinki. Immunohistochemical analysis using patient samples was approved by the Ethics Committee of Kyushu University Hospital (Approval ID: 30-363). Written informed consent was received from the patients prior to their inclusion in the study. We retrieved 126 patients with primary melanoma lesions who were treated at the Department of Dermatology of Kyushu University, Fukuoka, Japan, between July 2001 and March 2019. At least three experienced dermatopathologists confirmed the diagnosis. Clinical and demographic data of patients were collected from the patients' files and analyzed.

\subsection{Immunohistological Analysis}

All formalin-fixed paraffin-embedded melanoma tissues were obtained from the archives of Kyushu University Hospital. Immunohistochemistry staining was performed as reported previously with slight modifications $[47,48]$. Sections were incubated with following primary antibodies; rabbit anti-human NECTIN4 (1:150, Abcam; ab192033) for 30 min or with mouse anti-human VE1 (1:100, Abcam; ab228461) for $90 \mathrm{~min}$ at room temperature. After incubation with N-Histofine Simple Stain AP MULTI (Nichirei Biosciences; 414261) secondary antibody for $30 \mathrm{~min}$, sections were treated with FastRed II (Nichirei Biosciences; 415261) and counterstained with hematoxylin.

For immuno-double staining, antigen retrieval was performed with Heat Processor Solution pH9 (Nichirei Biosciences; 715291) at $100{ }^{\circ} \mathrm{C}$ for $40 \mathrm{~min}$. Sections were then incubated with mouse anti-human SOX10 (prediluted, Nichirei Biosciences; 418241) for 30 min at room temperature. N-Histofine Simple Stain AP MULTI and Perma Blue Plus/AP (Diagnostic BioSystems, Inc., Pleasanton, CA, USA; K058) were used as a secondary antibody and chromogen, respectively. After endogenous peroxidase blockade with $3 \% \mathrm{H}_{2} \mathrm{O}_{2}$ (Nichirei Biosciences), sections were incubated with rabbit anti-human NECTIN4 for 30 min and further treated with N-Histofine Simple Stain MAX-PO MULTI (Nichirei Biosciences; 724152) secondary antibody for $30 \mathrm{~min}$ at room temperature. Immunoreactions were detected by using 3,3'-diaminobenzidine tetrahydrochloride (Nichirei Biosciences, 725191) as a chromogenic substrate. In this method, SOX10- and NECTIN4-positive signals are shown in blue and in brown, respectively. 


\subsection{Evaluation of NECTIN4 Immunohistochemical Staining}

NECTIN4 expression in patients' melanoma tissue was evaluated by a semiquantitative method utilizing H-score [33]. NECTIN4 staining intensity was classified as follows: no staining (0), weakly positive (1+), moderately positive (2+), and strongly positive (3+) (Figure 1a). The staining of NECTIN4 in epidermis was categorized as $2+$ and considered as an internal control. The H-score was calculated by multiplying the percentage of NECTIN4positive cells and a staining intensity ranging from $0-3+$. Regarding VE1, tissues were considered as VE1-positive when at least $5 \%$ of melanoma cells were stained for VE1 according to the previous reports [47,48]. Two dermatologists (M.M. and T.I.), who were blinded to the clinical information, independently assessed NECTIN4 expression in the sections. Images were captured using a microscope (Nikon Corporation; ECLIPSE 80i).

\subsection{Statistics}

Quantitative results from at least three experiments are indicated as mean \pm standard deviation. GraphPad Prism7 software (GraphPad Software, San Diego, CA, USA) was used for statistical analyses. The differences between two groups were assessed by Student's unpaired two-tailed $t$-test. Fisher's exact test was applied to analyze the relationship between two variables. Patients' survival (MSS, DFS, and OS) was calculated using the Kaplan-Meier method and the log-rank test. For multivariate survival analysis, the multivariate Cox proportional hazards regression was applied. $p$-value $<0.05$ was considered as statistical significance.

\section{Conclusions}

In conclusion, we have investigated the expression and roles of NECTIN4 in melanoma. NECTIN4 was shown to be frequently expressed in BRAF-mutated melanoma. NECTIN4targeted therapy with ADCs, such as enfortumab vedotin, is a potential candidate for treating melanoma with BRAF-mutation and BRAFi-resistant melanomas, and its efficacy needs to be assessed in future research.

Supplementary Materials: The following are available online at https:/ /www.mdpi.com/1422-006 7/22/2/976/s1. Supplementary Figure S1: NECTIN4 and SOX10 expression in melanoma tissues. Supplementary Figure S2: H-score of NECTIN4 staining. Supplementary Figure S3: EGFR and MEK/ERK signal is activated in dabrafenib-resistant cell lines. Supplementary Figure S4: pAkt/Akt ratio in melanoma cell lines under the treatment with LY294002. Supplementary Figure S5: Knockdown efficiency of NECTIN4 and pAkt/Akt ratio during 24-72 $\mathrm{h}$ after transfection in MEL1617 and MEL1617-DR cells. Supplementary Figure S6: Knockdown efficiency of NECTIN4 and pAkt/Akt ratio during 24-72 $\mathrm{h}$ after transfection in SKMEL28 and SKMEL28-DR cells.

Author Contributions: Conceptualization, T.I.; methodology, Y.T., C.-H.S. and T.I.; validation, Y.T., M.M., M.F. and T.I.; formal analysis, Y.T., M.M. and T.I.; investigation, Y.T., M.M. and T.I.; resources, C.-H.S., M.F. and T.I.; data curation, Y.T., M.M. and T.I.; writing—original draft preparation, Y.T., M.M. and T.I.; writing-review and editing, Y.T., M.M., C.-H.S., M.F. and T.I.; visualization, Y.T. and M.M.; supervision, M.F. and T.I.; project administration, T.I.; funding acquisition, T.I. All authors have read and agreed to the published version of the manuscript.

Funding: This research was funded by grants from the Takeda Science Foundation and the Japan Society for the Promotion of Science KAKENHI, Grant Number 19K16867.

Institutional Review Board Statement: The study was conducted according to the guidelines of the Declaration of Helsinki, and approved by the Institutional Review Board of Kyushu University Hospital (approval ID: 30-363, approved on 27 November 2018).

Informed Consent Statement: Informed consent was obtained from all subjects involved in the study.

Data Availability Statement: The data presented in this study are available in the main text and the Supplementary Figures.

Acknowledgments: We thank all patients who participated in this work. We also thank the Takeda Science Foundation and the Japan Society for the Promotion of Science for their financial supports. 
Conflicts of Interest: The authors declare no conflict of interest.

$\begin{array}{ll}\text { Abbreviations } \\ \text { NECTIN4 } & \text { NECTIN cell adhesion molecule } 4 \\ \text { BRAFi } & \text { BRAF inhibitor } \\ \text { MEKi } & \text { MEK inhibitor } \\ \text { ADC } & \text { Antibody-drug conjugate } \\ \text { PI } & \text { Propidium iodide } \\ \text { qRT-PCR } & \text { Quantitative reverse transcription polymerase chain reaction } \\ \text { DR } & \text { Dabrafenib-resistant } \\ \text { MMAE } & \text { Monomethyl auristatin E } \\ \text { DFS } & \text { Disease-free survival } \\ \text { MSS } & \text { Melanoma-specific survival } \\ \text { OS } & \text { Overall survival } \\ \text { CCK-8 } & \text { Cell Counting Kit- } 8\end{array}$

\section{References}

1. Rastrelli, M.; Tropea, S.; Rossi, C.R.; Alaibac, M. Melanoma: Epidemiology, risk factors, pathogenesis, diagnosis, and classification. In Vivo 2014, 28, 1005. [PubMed]

2. Erdei, E.; Torres, M. A new understanding in the epidemiology of melanoma. Expert Rev. Anticancer Ther. 2010, 10, 1811-1818. [CrossRef] [PubMed]

3. Parkin, D.M.; Bray, F.; Ferlay, J.; Pisani, P. Estimating the world cancer burden: Globocan 2000. Int. J. Cancer 2001, 94, 153-156. [CrossRef] [PubMed]

4. $\quad$ Robert, C.; Long, G.V.; Brady, B.; Dutriaux, C.; Maio, M.; Mortier, L.; Hassel, J.C.; Rutkowski, P.; McNeil, C.; Kalinka-Warzocha, E.; et al. Nivolumab in preciously untreated melanoma without BRAF mutation. N. Engl. J. Med. 2015, 372, 320-330. [CrossRef]

5. Hennequin, C.; Rio, E.; Mahé, M.A. Radiotherapy of skin cancers. Cancer Radiother. 2016, 20, S249-S255. [CrossRef]

6. Franklin, C.; Livingstone, E.; Roesch, A.; Shilling, B.; Scgadendorf, D. Immunotherapy in melanoma: Recent advances and future directions. Eur. J. Surg. Oncol. 2017, 43, 604-611. [CrossRef]

7. Mahoney, K.M.; Freeman, G.J.; McDermott, D.F. The next immune-checkpoint inhibitors: PD-1/PD-L1 blockade in melanoma. Clin. Ther. 2015, 37, 764-782. [CrossRef]

8. Gide, T.N.; Wilmott, J.S.; Scolyer, R.A.; Long, G.V. Primary and acquired resistance to immune checkpoint inhibitors in metastatic melanoma. Clin. Cancer Res. 2017, 24, OF1-OF11. [CrossRef]

9. Shergold, A.L.; Millar, R.; Nibbs, R.J.B. Understanding and overcoming the resistance of cancer PD-1/PD-LI blockade. Pharmacol. Res. 2019, 145, 104258. [CrossRef]

10. Bradish, J.R.; Cheng, L. Molecular pathology of malignant melanoma: Changing the clinical practice paradigm toward a personalized approach. Hum. Pathol. 2014, 45, 1315-1326. [CrossRef]

11. Davies, H.; Bignell, G.R.; Cox, C.; Stephens, P.; Edkins, S.; Clegg, S.; Teague, J.; Woffendin, H.; Garnett, M.J.; Bottomley, W.; et al. Mutations of the BRAF gene in human cancer. Nature 2002, 417,949-954. [CrossRef] [PubMed]

12. Pavri, S.N.; Clune, J.; Ariyan, S.; Narayan, D. Malignant melanoma: Beyond the basics. Plast. Reconstr. Surg. 2016, 138, 330-340. [CrossRef] [PubMed]

13. Ascierto, P.A.; Kirkwood, J.M.; Grob, J.-J.; Simeone, E.; Grimaldi, A.M.; Maio, M.; Palmieri, G.; Testori, A.; Marincola, F.M.; Mozzillo, N. The role of BRAF V600 mutation in melanoma. J. Transl. Med. 2012, 10, 85. [CrossRef] [PubMed]

14. Hauschild, A.; Grob, J.-J.; Demidov, L.V.; Jouary, T.; Gutzmer, R.; Millward, M.; Rutkowski, P.; Blank, C.U.; Miller Jr, W.H.; Kaempgen, E.; et al. Dabrafenib in BRAF-mutated metastatic melanoma: A multicenter, open-label, phase 3 randomised controlled trial. Lancet 2012, 380, 358-365. [CrossRef]

15. Poulikakos, P.I.; Persaud, Y.; Janakiraman, M.; Kong, X.; Ng, C.; Moriceau, G.; Shi, H.; Atefi, M.; Titz, B.; Gabay, M.T.; et al. RAF inhibitor resistance is mediated by dimerization of aberrantly spliced BRAF(V600E). Nature 2012, 480, 387-390. [CrossRef]

16. Hirata, E.; Girotti, M.R.; Viros, A.; Hooper, S.; Spencer-Dene, B.; Matsuda, M.; Larkin, J.; Marais, R.; Sahai, E. Intravital imaging reveals how BRAF inhibition generates drug-tolerant microenvironments with high integrin $\beta 1 / F A K$ signaling. Cancer Cell 2015, 27, 574-588. [CrossRef]

17. Samanta, D.; Almo, S.C. Nectin family of cell-adhesion molecules: Structural and molecular aspects of function and specificity. Cell Mol. Life Sci. 2015, 72, 645-658. [CrossRef]

18. Rikitake, Y.; Mandai, K.; Takai, Y. The role of nectins in different types of cell-cell adhesion. J. Cell Sci. 2012, 125, 3713-3722. [CrossRef]

19. Ogita, H.; Ikeda, W.; Takai, Y. Roles of cell adhesion molecules nectin and nectin-like molecule-5 in the regulation of cell movement and proliferation. J. Microsc. 2008, 231, 455-465. [CrossRef]

20. Takai, Y.; Irie, K.; Shimizu, K.; Sakisaka, T.; Ikeda, W. Nectins and nectin-like molecules: Roles in cell adhesion, migration, and polarization. Cancer Sci. 2003, 94, 655-667. [CrossRef] 
21. Miyoshi, J.; Takai, Y. Nectin and nectin-like molecules: Biology and pathology. Am. J. Nephrol 2007, 27, 590-604. [CrossRef] [PubMed]

22. Nishiwada, S.; Sho, M.; Yasuda, S.; Shimada, K.; Yamato, I.; Akahori, T.; Kinoshita, S.; Nagai, M.; Konishi, N.; Nakajima, Y. Nectin-4 expression contributes to tumor proliferation, angiogenesis and patient prognosis in human pancreatic cancer. J. Exp. Clin. Cancer Res. 2015, 34, 30. [CrossRef] [PubMed]

23. Fabre-Lafay, S.; Monville, F.; Garrido-Urbani, S.; Berruyer-Pouyet, C.; Ginestier, C.; Reymond, N.; Finetti, P.; Sauvan, R.; Adélaïde, J.; Geneix, J. Nectin-4 is a new histological and serological tumor associated marker for breast cancer. BMC Cancer 2007, 7, 73. [CrossRef]

24. Challita-Eid, P.M.; Satpayev, D.; Yang, P.; An, Z.; Morrison, K.; Shostak, Y.; Raitano, A.; Nadell, R.; Liu, W.; Lortie, D.R.; et al. Enfortumab vedotin antibody-drug conjugate targeting nectin-4 is a highly potent therapeutic agent in multiple preclinical cancer models. Cancer Res. 2016, 76, 3003-3013. [CrossRef] [PubMed]

25. Manabe, S.; Yamaguchi, Y.; Matsumoto, K.; Fuchigami, H.; Kawase, T.; Hirose, K.; Mitani, A.; Sumiyoshi, W.; Kinoshita, T.; Abe, J.; et al. Characterization of antibody products obtained through enzymatic and nonenzymatic glycosylation reactions with a glycan oxazoline and preparation of a homogeneous antibody-drug conjugate via Fc N-glycan. Bioconjug. Chem. 2019, 30, 1343-1355. [CrossRef]

26. Beck, A.; Goetsch, L.; Dumontet, C.; Corvaia, N. Strategies and challenges for the next generation of antibody-drug conjugates. Nat. Rev. Drug Discov. 2017, 16, 315-337. [CrossRef]

27. Carter, P.J.; Lazar, G.A. Next generation antibody drugs: Pursuit of the 'high-hanging fruit'. Nat. Rev. Drug Discov. 2017, 17, 197-223. [CrossRef]

28. Kaplon, H.; Reichert, J.M. Antibodies to watch in 2019. MAbs 2019, 11, 219-238. [CrossRef]

29. Rosenberg, J.E.; O’Donnell, P.H.; Balar, A.V.; McGregor, B.A.; Heath, E.I.; Yu, E.Y.; Galsky, M.D.; Hahn, N.M.; Gartner, E.M.; Pinelli, J.M.; et al. Pivotal trial of enfortumab vedotin in urothelial carcinoma after platinum and anti-programmed death 1/programmed death ligand 1 therapy. J. Clin. Oncol. 2019, 37, 2592-2600. [CrossRef]

30. Mollo, M.R.; Antonini, D.; Mitchell, K.; Fortugno, P.; Costanzo, A.; Dixon, J.; Brancati, F.; Missero, C. P63-dependent and independent mechanisms of nectin-1 and nectin-4 regulation in the epidermis. Exp. Dermatol. 2015, 24, 114-119. [CrossRef]

31. Brancati, F.; Fortugno, P.; Bottillo, I.; Lopez, M.; Josselin, E.; Boudghene-Stambouli, O.; Agolini, E.; Bernardini, L.; Bellacchio, E.; Iannicelli, M.; et al. Mutations in PVRL4, encoding cell adhesion molecule nectin-4, cause ectodermal dysplasia-syndactyly syndrome. Am. J. Hum. Genet. 2010, 87, 265-273. [CrossRef] [PubMed]

32. Murata, M.; Ito, T.; Tanaka, Y.; Kaku-Ito, Y.; Furue, M. NECTIN4 expression in extramammary Paget's disease: Implication of a new therapeutic target. Int. J. Mol. Sci. 2020, 21, 5891. [CrossRef] [PubMed]

33. McClelland, R.A.; Finlay, P.; Walker, K.J.; Nicholson, D.; Robertson, J.F.; Blamey, R.W.; Nicholson, R.I. Automated quantification of immunocytochemically localized estrogen receptors in human breast cancer. Cancer Res. 1990, 50, 3545-3550. [PubMed]

34. Kakadia, S.; Yarlagadda, N.; Awad, R.; Kundranda, M.; Niu, J.; Naraev, B.; Mina, L.; Dragovich, T.; Gimbel, M.; Mahmoud, F. Mechanisms of resistance to BRAF and MEK inhibitors and clinical update of US Food and Drug Administration-approved targeting therapy in advanced melanoma. Onco. Targets Ther. 2018, 11, 7095-7107. [CrossRef] [PubMed]

35. Torres-Collado, A.X.; Knott, J.; Jazirehi, A.R. Reversal of resistance in targeted therapy of metastatic melanoma: Lessons learned from Vemurafenib (BRAFV600E-specific inhibitor). Cancers 2018, 10, 157. [CrossRef] [PubMed]

36. Turajlic, S.; Furney, S.; Stamp, G.; Rana, S.; Ricken, G.; Oduko, Y.; Saturno, G.; Springer, C.; Hayes, A.; Gore, M.; et al. Wholegenome sequencing reveals complex mechanisms of intrinsic resistance to BRAF inhibition. Ann. Oncol. 2014, 25, 959-967. [CrossRef]

37. Luebker, S.A.; Koepsell, S.A. Diverse mechanisms of BRAF inhibitor resistance in melanoma inhibitor resistance in melanoma identified in clinical and preclinical studies. Front. Oncol. 2019, 9, 268. [CrossRef]

38. Takahashi, S.; Uemura, M.; Kimura, T.; Kawasaki, Y.; Takamoto, A.; Yamaguchi, A.; Melhem-Bertrandt, A.; Gartner, E.M.; Inoue, T.; Akazawa, R.; et al. A phase I study of enfortumab vedotin in Japanese patients with locally advanced or metastatic urothelial carcinoma. Investig. New Drug 2020, 38, 1056-1066. [CrossRef]

39. Zhang, Y.; Liu, S.; Wang, L.; Wu, Y.; Hao, J.; Wang, Z.; Lu, W.; Wang, X.-A.; Zhang, F.; Cao, Y.; et al. A novel PI3K/AKT signaling axis mediated Nectin-4-induced gallbladder cancer cell proliferation, metastasis and tumor growth. Cancer Lett. 2016, 375, 179-189. [CrossRef]

40. Siddharth, S.; Goutam, K.; Das, S.; Nayak, A.; Nayak, D.; Sethy, C.; Wyatt, M.D.; Kundu, C.N. Nectin-4 is a breast cancer stem cell marker that induces WNT/ $\beta$-catenin signaling via Pi3k/Akt axis. Int. J. Biochem. Cell Biol. 2017, 89, 85-94. [CrossRef]

41. Zhang, Y.; Chen, P.; Yin, W.; Ji, Y.; Shen, Q.; Ni, Q. Nectin-4 promotes gastric cancer progression via the PI3K/AKT signaling pathway. Hum. Pathol. 2018, 72, 107-116. [CrossRef] [PubMed]

42. Hao, R.-T.; Zheng, C.; Wu, C.-Y.; Xia, E.-J.; Zhou, X.-F.; Quan, R.-D.; Zhang, X.-H. NECTIN4 promotes papillary thyroid cancer cell proliferation, migration, and invasion and triggers EMT by activating AKT. Cancer Manag. Res. 2019, 11, 2565-2578. [CrossRef]

43. Villanueva, J.; Vultur, A.; Lee, J.T.; Somasundaram, R.; Fukunaga-Kalabis, M.; Cipolla, A.K.; Wubbenhorst, B.; Xu, X.; Gimotty, P.A.; Kee, D.; et al. Acquired resistance to BRAF inhibitors mediated by a RAF kinase switch in melanoma can be overcome by cotargeting MEK and IGF-1R/PI3K. Cancer Cell 2010, 18, 683-695. [CrossRef] 
44. Sosman, J.A.; Kim, K.B.; Schuchter, L.; Gonzalez, R.; Pavlick, A.C.; Weber, J.S.; McArthur, G.A.; Hutson, T.E.; Moschos, S.J.; Flaherty, K.T.; et al. Survival in BRAF V600-mutant advanced melanoma treated with vemurafenib. N. Engl. J. Med. 2012, 366, 707-714. [CrossRef] [PubMed]

45. Flaherty, K.T.; Infante, J.R.; Daud, A.; Gonzalez, R.; Kefford, R.F.; Sosman, J.; Hamid, O.; Schuchter, L.; Cebon, J.; Ibrahim, N.; et al. Combined BRAF and MEK inhibition in melanoma with V600 mutations. N. Engl. J. Med. 2012, 367, 1694-1703. [CrossRef] [PubMed]

46. Tanaka, Y.; Uchi, H.; Ito, T.; Furue, M. Indirubin-pregnane X receptor-JNK axis accelerates skin wound healing. Sci. Rep. 2019, 9, 18174. [CrossRef]

47. Ito, T.; Kaku-Ito, Y.; Murata, M.; Furue, K.; Shen, C.-H.; Oda, Y.; Furue, M. Immunohistochemical BRAF V600E expression and intratumor BRAF V600E heterogeneity in acral melanoma: Implication in melanoma-specific survival. J. Clin. Med. 2020, 9, 690. [CrossRef]

48. Ito, T.; Kaku-Ito, Y.; Murata, M.; Ichiki, T.; Kuma, Y.; Tanaka, Y.; Ide, T.; Ohno, F.; Wada-Ohno, M.; Yamada, Y.; et al. Intra- and inter-tumor BRAF heterogeneity in acral melanoma: An immunohistochemical analysis. Int. J. Mol. Sci. 2019, 20, 6191. [CrossRef] 